\title{
Relation of behavior of copepod juveniles to potential predation by omnivorous copepods: an empirical-modeling study
}

\author{
Houshuo Jiang ${ }^{1, *}$, Gustav-Adolf Paffenhöfer ${ }^{2, * *}$ \\ ${ }^{1}$ Department of Applied Ocean Physics and Engineering, Woods Hole Oceanographic Institution, Woods Hole, \\ Massachusetts 02543, USA \\ ${ }^{2}$ Skidaway Institute of Oceanography, 10 Ocean Science Circle, Savannah, Georgia 31411, USA
}

\begin{abstract}
An empirical-modeling study was carried out to examine the motion behavior of copepod nauplii in relation to their potential predation by omnivorous copepods. First, video observations were taken on the encounters of Centropages velificatus, Paracalanus aculeatus, Paracalanus quasimodo and Temora stylifera nauplii with free-swimming adult females of $C$. velificatus. By examining each female's behavior, the observed encounters were arranged into 3 categories: (1) quasi-steady, (2) unsteady, and (3) unsteady with body rotation. We found that a wide spectrum of motion behaviors contributes to the generation of hydrodynamic signals. A hydrodynamic model was developed to analyze 4 encounters under the quasi-steady category. The model takes into account the effects of the finite-sized body morphology and the no-slip boundary condition imposed at the surface of the nauplius. Therefore, the model is able to calculate the tip-base velocity differences, as well as the tip-base shear rates over the length of the setae of the A1 (first antennae) of the nauplii, resulting from the flow disturbances generated by a steadily approaching $C$. velificatus female. When the tip-base shear rates around its A1 setae reached the range of 3.0 to $4.8 \mathrm{~s}^{-1}$, a $C$. velificatus nauplius, moving only occasionally, detected the approaching female copepod. By contrast, a P. quasimodo nauplius and a $T$. stylifera nauplius, both moving continuously by beating their cephalic appendages, did not detect the female, even when the tip-base shear rates reached the range of 5.2 to $6.2 \mathrm{~s}^{-1}$ for the former and 8.4 to $11.4 \mathrm{~s}^{-1}$ for the latter. The modeling results also reveal the cause of the difference in the sensitivity to hydrodynamic signals. Nauplii moving only occasionally have a much weaker noise field (originating from the naupliar self-generated flow) around their A1 setae than those moving their cephalic appendages continuously to achieve a smooth and continuous motion pattern, and therefore are better suited to perceiving nearby predators. This model provides a mechanistic understanding as to why continuously moving nauplii are preyed upon at a higher rate than those moving intermittently.
\end{abstract}

KEY WORDS: Copepod $\cdot$ Nauplii $\cdot$ Predator avoidance $\cdot$ Swimming/motion behavior $\cdot$ Mechanoreception $\cdot$ Hydrodynamic model $\cdot$ Hydrodynamic signals $\cdot$ Noise field

\section{INTRODUCTION}

Nauplii are considered 'the most abundant type of multicellular animal in existence' (Fryer 1986). They are the early juvenile stages of planktonic and benthic crustaceans, including almost all copepod species. They are frequently more abundant than their older relatives in the marine epiplanktonic environment (e.g. Paffenhöfer et al. 1984). The reason for this is mortality which can be due to (a) natural death (e.g. because of food limitation, Paffenhöfer 1970, Hart 1997), or (b) predation (e.g. Kiørboe \& Sabatini 1994). Mortality of zooplankton in the ocean is extremely difficult to quantify (e.g. Marine Zooplankton Colloquium 1 1989, Ohman \& Wood 1995), therefore environmental rates of mortality of zooplankton are seldom 
obtained. There is uncertainty not only about the environmental rates of mortality but also to what extent these rates are due to food limitation or predation.

Predation on and by copepods has been an issue (e.g. Kerfoot 1978, Ohman 1988) and remains an issue despite advances in empirical and modeling efforts (e.g. Kiørboe \& Visser 1999, Kiørboe et al. 1999, Visser 2001). Predation and its avoidance depend on different variables including hydrodynamic perception by both prey and predator, as well as the capture ability of the predator, and the escape ability of the potential prey. It is known that nauplii of some copepod species appear to be more vulnerable to predation than others and also later copepodid stages tend to be less vulnerable than younger nauplii (Mullin \& Brooks 1970, Landry 1978, Paffenhöfer \& Knowles 1980, Titelman 2001, Eiane et al. 2002). However the mechanisms underlying the extent of vulnerability are largely unknown.

The difference in vulnerability to predation may be due to differences in motion/swimming behaviors of nauplii of different species. Movement patterns range from continuous to occasional, and nauplii can move at different velocities, and can perform different directional motions (Buskey et al. 1993, Paffenhöfer et al. 1996, Titelman 2001). Numerous copepod species are known to be predators on nauplii and early copepodid stages (e.g. Anraku \& Omori 1963, Gauld 1966). They range from continuous movers like Euchaeta rimana (Yen 1988), to those swimming with intermittent sinking, e.g. Centropages typicus and C. hamatus (Tiselius \& Jonsson 1990), to those copepods with longer periods of inactivity and intermittent motion, e.g. Oithona spp. (Svensen \& Kiørboe 2000, Paffenhöfer \& Mazzocchi 2002).

Various studies show that perception by both a prey and a predator, their motion behavior, and also the size of the prey determine whether a prey is eventually captured (e.g. Kerfoot 1978). A certain size range is optimal for capture and ingestion as shown by Landry \& Fagerness (1988) for Euchaeta elongata offered copepodids of various lengths. The stronger the prey motion, the higher the probability of detection by a predatory copepod (e.g. Kiørboe \& Visser 1999, Titelman 2001). A model on encounter probabilities in zooplankton revealed 2 optimal strategies; ambushers preying on fast-moving prey, and cruising predators preying on slow-moving animals (Gerritsen \& Strickler 1977).

Prey behavior determines not only the prey's perception by a predator but also its perception of a predator (Paffenhöfer 1998). A nauplius which moves slowly and continuously broadcasts a weak signal but cannot perceive hydrodynamic signals well because of the constant motion of its 3 appendage pairs (e.g. Paracalanus, Temora). A copepodid which also moves continuously, but has non-moving first antennae with non-moving terminal setae, can perceive even slight hydrodynamic signals and is therefore less prone to predation as demonstrated by the experiments of Landry (1978) with Labidocera trispinosa as a predator. Nauplii which move intermittently (e.g. Acartia, Oithona, Centropages) usually create a stronger hydrodynamic signal than those continuously moving slowly but they can 'listen' between moves and therefore perceive a predator early (Centropages, Paffenhöfer \& Knowles 1980; Acartia, Titelman 2001). Titelman \& Kiørboe (2003) demonstrated that the motion behavior of copepod nauplii is tightly linked to their sensitivity to hydrodynamic signals. Nauplii moving intermittently (jump-sink) have highest sensitivity (i.e. require lowest threshold deformation rates to initiate an escape response); nauplii swimming continuously have lowest sensitivity (i.e. require highest threshold flow deformation rates to initiate an escape response).

Hydrodynamic modeling studies can be employed to understand hydrodynamic signal perception between a predator and a prey. Indeed, simple solutions based on the Stokes flow models have often been used to approximate the flow field created by a copepod (as either a prey or predator), and then the transmitted hydrodynamic signals were quantified by calculating flow quantities, such as velocity magnitude, deformation rate, vorticity and fluid acceleration from the Stokes flow field. For example, the flow field due to a point force in an infinite domain was used to model the feeding current created by a hovering copepod (Tiselius \& Jonsson 1990). The feeding current created by a hovering copepod was also modeled by the 'spherical pump' solution, i.e. the flow for a translating sphere with a frame of reference fixed with respect to the far field fluid (Kiørboe \& Visser 1999). To model a swimming or sinking copepod, the Stokes solution for a translating sphere moving with a constant velocity was utilized (Tiselius \& Jonsson 1990, Kiørboe \& Visser 1999). The Stokes flow due to a force dipole was used to model the flow created by a neutrally buoyant, selfpropelled body moving at uniform velocity (Svensen \& Kiørboe 2000, Visser 2001). A new Stokes flow model was developed by Jiang et al. (2002a), in which the model copepod consists of a spherical body and a single appendage represented by a point force outside the spherical body. This model is different from previous models in that it is a self-propelled body model and is at the same time able to take into account the effect due to the excess weight of the copepod. (Note that the effect due to the excess weight may be a dominant component in generating the flow around a negatively buoyant, free-swimming copepod.) For arbitrary steady motion, the direction and magnitude of the point force can be adjusted to maintain the balance among the 
negative buoyancy, drag, and thrust acting on the copepod. In addition, numerical simulations were used to quantify the hydrodynamic signals for the perception of inert particles by copepods (Bundy et al. 1998) and for the detection between 2 copepods of comparable size (Jiang et al. 2002b).

However, a more sophisticated model which more closely resembles natural conditions is needed. The model should take into account the self-propelled body motion of both a prey and a predator with various behaviors. The information on the excess weight of both the prey and the predator also needs to be taken into account. An assumption underlying the mechanoreception between a prey and a predator is that the signal receiver perceives a hydrodynamic disturbance by the bending of its mechanoperceptive setae (Strickler \& Bal 1973, Yen et al. 1992). A velocity difference between the signal receiver and the ambient water may cause the setae to bend (Viitasalo et al. 1998, Kiørboe \& Visser 1999, Kiørboe et al. 1999, Jiang et al. 2002b). Thus, to quantify the hydrodynamic signals perceived by a prey due to an approaching predator, the flow disturbance generated by the predator is required to satisfy the no-slip boundary condition at the body surface of the prey. Parameters such as the body size of the prey, and the lengths and locations of the setae relative to the prey body need to be involved in the model. In addition, the motion pattern of the prey's cephalic appendages needs to be considered because the motion of the cephalic appendages and body of the prey creates a naupliar self-generated flow, a noise field, around the prey's mechanoperceptive setae. In this work we present such a model. The model is then used to calculate the hydrodynamic signals potentially perceptible to a nauplius for $4 \mathrm{ob}-$ served nauplius-copepod encounter events. Our purpose is to test the hypothesis that a nauplius intermittently moving its cephalic appendages (studded with setae having mechanoperceptive structures) can more easily perceive the hydrodynamic signals generated due to an approaching copepod than a nauplius moving its cephalic appendages continuously. The present work is an empirical-modeling study. High-resolution video observations on encounters between a nauplius and a copepod provide positions and velocities of both; the data are then placed into the hydrodynamic model and the hydrodynamic signals then quantified.

\section{EMPIRICAL VIDEO OBSERVATIONS}

Materials and methods. Our studies utilized adult females of the calanoid Centropages velificatus as predators, and naupliar stages III to VI of Centropages velificatus, Paracalanus quasimodo, Paracalanus acu- leatus and Temora stylifera as prey. All 4 species are frequently encountered on the southeastern (SE) US continental shelf (Bowman 1971). C. velificatus females, previously called C. furcatus (Bowman 1971, Paffenhöfer \& Knowles 1980) are known to prey on nauplii. They alternate between creating a feeding current while simultaneously moving obliquely upwards, and sinking, i.e. not moving any appendages.

The 4 prey species move differently and therefore produce different hydrodynamic signals. Nauplii of Centropages velificatus move intermittently at brief intervals at $2.7 \mathrm{~mm} \mathrm{~s}^{-1}$, those of the neritic Paracalanus quasimodo and the oceanic $P$. aculeatus move continuously in an even hop-like motion producing a spirallike pattern, at 1.34 and $0.48 \mathrm{~mm} \mathrm{~s}^{-1}$, respectively, while those of Temora stylifera move continuously in 3-D in a smooth manner while creating a feeding current (Paffenhöfer et al. 1996). Also, the 4 prey species appear to have different predator perception abilities.

Adult females of Centropages velificatus were collected on the SE US shelf at temperatures ranging from 19 to $23^{\circ} \mathrm{C}$ with oblique tows using a 41 codend while the RV 'Bluefin' was drifting. These females were removed immediately from the samples, placed in 21 screwcap bottles and kept on a Ferris wheel at $0.2 \mathrm{rpm}$ at $20^{\circ} \mathrm{C}$. They were offered the dinoflagellate Gymnodinium nelsoni at 0.3 to $1.0 \mathrm{~mm}^{3} \mathrm{l}^{-1}$, and were used for videotaping within 2 to $5 \mathrm{~d}$ after collection. Nauplii of the 4 previously mentioned species were obtained from adult females collected similarly as above. These females were offered G. nelsoni at $\sim 0.5 \mathrm{~mm}^{3} \mathrm{l}^{-1}$ and the small flagellate Rhodomonas baltica at $0.3 \mathrm{~mm}^{3} \mathrm{l}^{-1}$; the latter was used as food for the hatched nauplii. Prior to the videotaping, the $C$. velificatus females were offered prey nauplii in 21 rotating jars (10 to 20 nauplii $\mathrm{l}^{-1}$ ), in order to precondition the females (Donaghay \& Small 1979).

All videotaping occurred in darkness in 31 plexiglass containers $(15 \times 15 \times 15 \mathrm{~cm})$ at $20^{\circ} \mathrm{C}$. Nauplius concentrations usually ranged from 10 to $20 \mathrm{l}^{-1}$, and those of females were $1 \mathrm{l}^{-1}$. The containers usually had concentrations of $\sim 0.3 \mathrm{~mm}^{3} \mathrm{l}^{-1}$ of Rhodomonas baltica and $\sim 0.1 \mathrm{~mm}^{3} \mathrm{l}^{-1}$ of Gymnodinium nelsoni. Observations were made at $830 \mathrm{~nm}$ wavelength, with a modified CritterCam $^{\circledR}$ (Strickler 1985) which was mounted on a stage moving in 3-D. A free-swimming female could be followed via joystick control for times varying from seconds to more than $1 \mathrm{~h}$ continuously. This was recorded on S-VHS at 60 frames $\mathrm{s}^{-1}$. Resolution was $20 \mu \mathrm{m}$ which allowed us to resolve the nauplii's motion on the S-VHS tapes. Velocity analyses were only made when a female and a nauplius both remained in the plane of focus during their encounter. For each analysis we drew the positions of prey and predator from a 13 inch screen onto transparency sheets. From these 
we could evaluate the motions, velocities and respective behaviors of both prey and predator.

Results from empirical video observations. A number of video observations were obtained from the interactions of Centropages velificatus, Paracalanus aculeatus, Paracalanus quasimodo and Temora stylifera nauplii with free-swimming adult females of $C$. velificatus. Among them, 15 encounter events occurred in the vertical plane of focus and hence were analyzed. From the analysis, 15 diagrams were drawn from overlapping series of video frames. Of these, 6 are shown here as examples (Figs. 1 to 6 ). In each figure, the overlapped video frames are labeled with different colors. Thus the time course of the positions of both the nauplius and the female are shown. A stationary frame of reference was used. The time interval between 2 consecutive video frames is $1 / 60 \mathrm{~s}$. Based on the scale bar shown in each figure, the positions and velocity vectors of both the nauplius and the female were calculated. The resulting velocity vectors are also shown in each figure.

The present work focuses on a nauplius' detection of the hydrodynamic signals generated due to the selfpropelled motion of a female copepod relative to the nauplius. Generated hydrodynamic signals are largely dependent on the motion behavior of the female copepod. Therefore, our observations have been sorted into 3 categories: (1) quasi-steady, (2) unsteady, and (3) unsteady with body rotation, based on the motion behavior of the female copepod (Table 1). The 3 categories are able to cover a large number of possible patterns in nauplius-copepod interactions. In the quasisteady category, the female copepod's motion remains quasi-steady before and at detection by the nauplius (Figs. 1 \& 2, Events 1 \& 2 in Table 1). In the unsteady category, the unsteady linear accelerated/decelerated movement of the female copepod generates hydrodynamic signals, which the nauplius detects (Fig. 3, Event 3 in Table 1). In the unsteady with body rotation category, the hydrodynamic signals are generated due not only to the unsteady linear accelerated/decelerated body motion but also to the body rotation of the female copepod (Fig. 4, Event 4 in Table 1). Comparing the jumping-away reaction of the nauplius among the 3 categories, one may conclude that the nauplius' reaction is less strong for those nauplii in the encounter events under the quasi-steady category, as indicated by a smaller jumping-away speed, compared with nauplii in the encounter events under the other 2 categories. Presumably, the hydrodynamic signals generated are weaker in the quasi-steady category than in the other 2 categories.

Nauplii of different species may have different mechanoperceptive abilities in detecting an approaching predator, because nauplii of different species may
Centropages velificatus female vs. Centropages velificatus nauplius
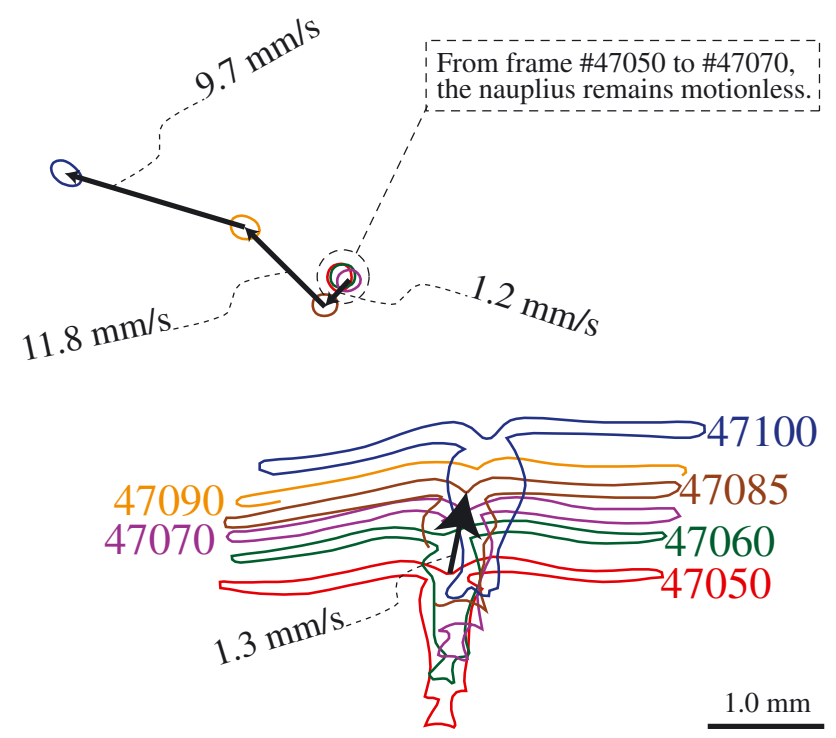

Fig. 1. Video sequence illustrating an encounter between a Centropages velificatus female and a $C$. velificatus nauplius (Event 1 in Table 1, quasi-steady category) as seen in a stationary frame of reference. The time interval between 2 consecutive video frames is $1 / 60 \mathrm{~s}$. A series of video frames is labeled by different colors. Velocity vectors of both the copepod and the nauplius were obtained by analyzing the video sequences, and are shown in the figure as large arrow with velocity magnitude for the copepod and small arrows for the nauplius. At frame \#47070 the nauplius detected the slow upward motion of the female and responded accordingly

\section{Centropages velificatus female vs. Centropages velificatus nauplius}

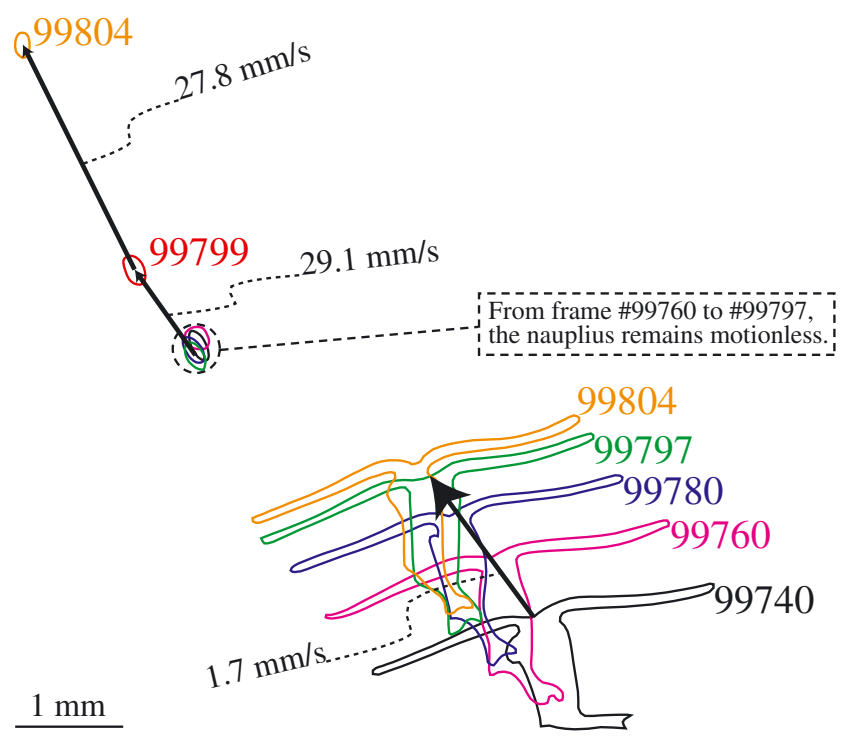

Fig. 2. Video sequence illustrating an encounter between a Centropages velificatus female and a $C$. velificatus nauplius (Event 2 in Table 1, quasi-steady category) as seen in a stationary frame of reference. At frame \#99797 the nauplius detected the female's swimming motion and responded quickly. See Fig. 1 legend for explanation of velocity vector annotation 
Table 1. Information on the encounters of Centropages velificatus females with nauplii of C. velificatus, Temora stylifera and Paracalanus quasimodo

\begin{tabular}{|c|c|c|c|c|c|c|c|c|}
\hline Event \# & $\begin{array}{l}\text { Nauplius } \\
\text { species }\end{array}$ & $\begin{array}{l}\text { Nauplius } \\
\text { motion prior } \\
\text { to perception }\end{array}$ & $\begin{array}{l}\text { Nauplius } \\
\text { escape velocity } \\
\left(\mathrm{mm} \mathrm{s}^{-1}\right)\end{array}$ & $\begin{array}{l}\text { Female } \\
\text { velocity } \\
\left(\mathrm{mm} \mathrm{s}^{-1}\right)\end{array}$ & $\begin{array}{l}\text { Original } \\
\text { nauplius } \\
\text { location }\end{array}$ & $\begin{array}{c}\text { Distance } \\
\text { nauplius-female at } \\
\text { perception (mm) }\end{array}$ & $\begin{array}{l}\text { Who } \\
\text { detected } \\
\text { whom }\end{array}$ & $\begin{array}{l}\text { Motion } \\
\text { category }\end{array}$ \\
\hline 1 (Fig. 1) & C. velificatus & Sinking slowly & $1.2-11.8$ & 1.3 upwards & $\begin{array}{l}\sim 3 \mathrm{~mm} \text { ahead } \\
\text { of } \text { left A1 }\end{array}$ & 1.9 & $\mathrm{~N}$ the $\%$ & Quasi-steady \\
\hline 2 (Fig. 2) & C. velificatus & Sinking slowly & $27.8-29.1$ & $\begin{array}{c}1.7 \text { obliquely } \\
\text { upwards }\end{array}$ & $\begin{array}{l}\sim 3.5 \mathrm{~mm} \text { away } \\
\text { from } \text { left A1 tip }\end{array}$ & 2.2 & $\mathrm{~N}$ the $\%$ & Quasi-steady \\
\hline 3 (Fig. 3) & C. velificatus & Sinking slowly & $0.7-12.3$ & $\begin{array}{c}2.3-3.8 \\
\text { upwards }\end{array}$ & $\begin{array}{l}\sim 2 \mathrm{~mm} \text { above } \\
\text { o cephalon }\end{array}$ & 1.4 & $\mathrm{~N}$ the $\mathrm{o}$ & Unsteady \\
\hline 4 (Fig. 4) & C. velificatus & $\begin{array}{l}\text { Moving very } \\
\text { slowly }\end{array}$ & $4.8-42$ & $\begin{array}{c}\text { initially } 2.0 \\
\text { upwards, then } \\
4.8-32 \text { jumping }\end{array}$ & $\begin{array}{l}\sim 3.5 \mathrm{~mm} \text { above } \\
\quad \text { right A1 }\end{array}$ & 0.9 & $\mathrm{~N}$ the o & $\begin{array}{l}\text { Unsteady } \\
\& \text { body } \\
\text { rotation }\end{array}$ \\
\hline 5 (Fig. 5) & T. stylifera & $\begin{array}{l}\text { Moving very } \\
\text { slowly or hovering }\end{array}$ & $20-64$ & 2.8 upwards & $\begin{array}{c}0.9 \mathrm{~mm} \\
\text { above o A1 }\end{array}$ & $<0.1$ & o the $\mathrm{N}$ & $\begin{array}{l}\text { Quasi-steady } \\
\text { before frame } \\
\quad \# 289099\end{array}$ \\
\hline 6 (Fig. 6) & P. quasimodo & $\begin{array}{l}\text { Moving very slowly } \\
\text { in a tight circle }\end{array}$ & $39-42$ & $\begin{array}{l}3.9 \text { upwards then } \\
16-44 \text { jumping }\end{array}$ & $\begin{array}{l}1.0 \mathrm{~mm} \text { above } \\
\text { tip of o A1 }\end{array}$ & $\sim 0.2$ & o the $\mathrm{N}$ & $\begin{array}{l}\text { Quasi-steady } \\
\text { before frame } \\
\quad \# 222309\end{array}$ \\
\hline
\end{tabular}

Centropages velificatus female vs. Centropages velificatus nauplius

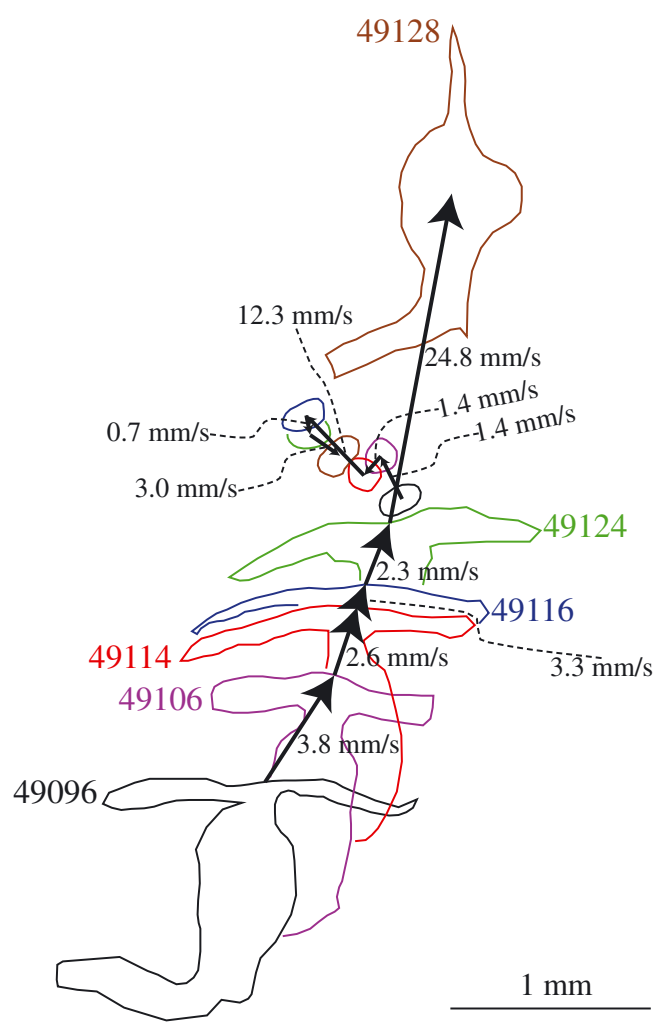

Fig. 3. Video sequence illustrating an encounter between a Centropages velificatus female and a C. velificatus nauplius (Event 3 in Table 1, unsteady category) as seen in a stationary frame of reference. It appears as if the nauplius perceived every step of the female's motion, as seen in the nauplius' motion behavior. The nauplius' moderate velocity responses and direction changes to the female's motion were probably to its advantage, i.e. not providing a pronounced signal to the predator. See Fig. 1 legend for explanation of velocity vector annotation have different motion behaviors (Paffenhöfer 1998). Observations of these differing abilities are presented in this paper. Next we present 2 encounter events of a Temora stylifera nauplius (Fig. 5, Event 5 in Table 1) and a Paracalanus quasimodo nauplius (Fig. 6, Event 6 in Table 1), respectively, with a free-swimming adult female of Centropages velificatus. These 2 encounter events are then compared with previously described encounter events between a $C$. velificatus nauplius and a $C$. velificatus adult female.

The 2 events illustrated in Figs. $5 \& 6$ are different from those of Centropages velificatus nauplii interacting with $C$. velificatus females (Figs. 1 \& 2). By comparing the nauplius-female interactions of these 4 figures, it appears that the perception ability of $C$. velificatus nauplii is better than that of Temora stylifera or Paracalanus quasimodo nauplii at detecting the hydrodynamic signals generated by a $C$. velificatus female. For the 2 events involving a T. stylifera nauplius and a $P$. quasimodo nauplius, the hydrodynamic signals generated by the $C$. velificatus female were stronger than the 2 events involving a $C$. velificatus nauplius, as indicated by a shorter distance and greater relative velocity between the prey and predator in the former 2 events; however, neither the $T$. stylifera nauplius nor the $P$. quasimodo nauplius detected the approaching C. velificatus female before the latter launched a capturing strike.

\section{MODELING STUDIES}

Naupliar self-generated flows. Whenever a nauplius moves its appendages, a naupliar self-generated flow exists around its body. Different motion patterns of the 


\section{Centropages velificatus female vs. Centropages velificatus nauplius}

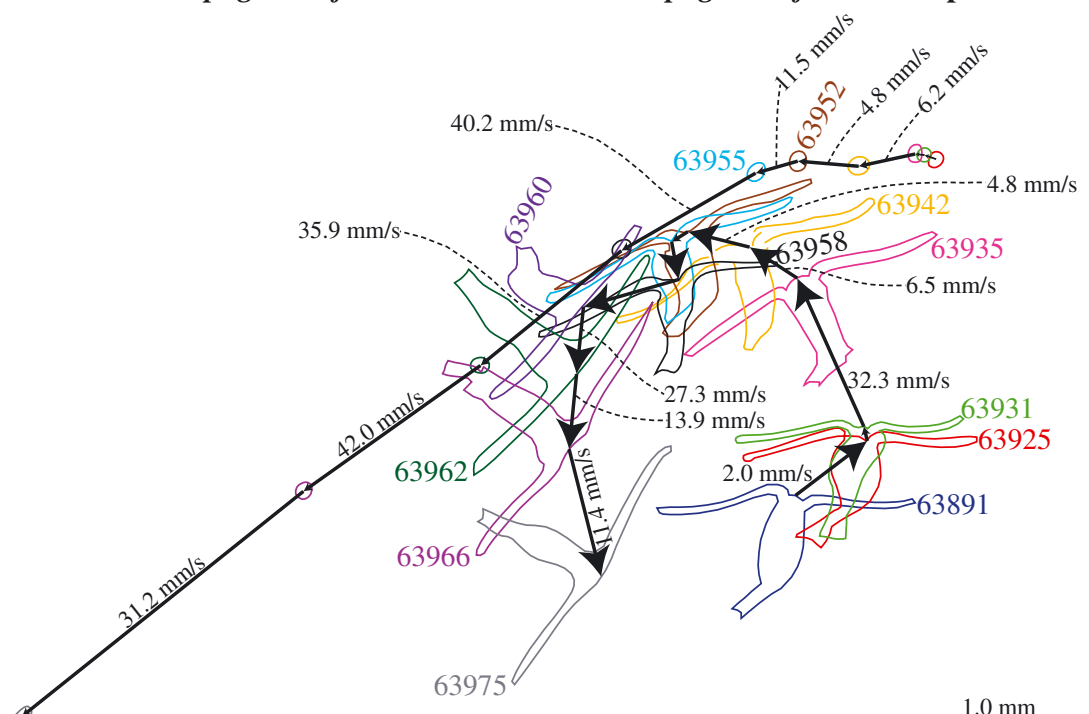

Fig. 4. Video sequence illustrating an encounter between a Centropages velificatus female and a $C$. velificatus nauplius (Event 4 in Table 1, unsteady with body rotation category) as seen in a stationary frame of reference. The nauplius responded to the acceleration of the female after frame \#63931 with a jump after frame \#63935, which amounts to $0.067 \mathrm{~s}$ time difference; this jump triggered more strikes by the female, involving a somersault, which resulted in the nauplius attempting to escape. See Fig. 1 legend for explanation of velocity vector annotation

\section{Centropages velificatus female vs. Temora stylifera nauplius}

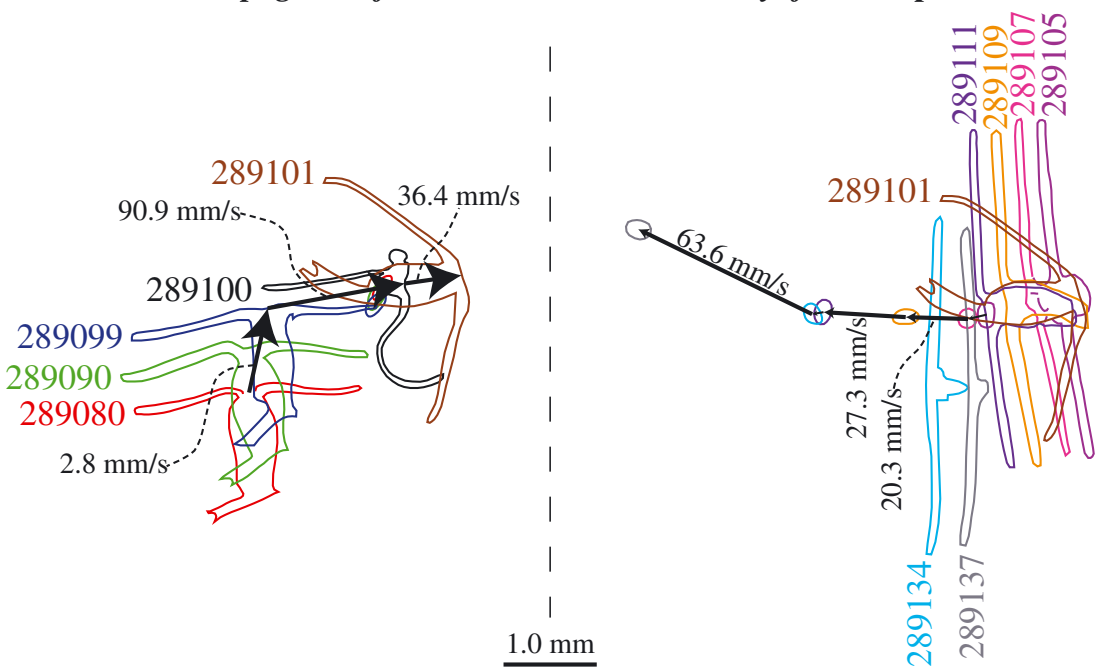

Fig. 5. Video sequence illustrating an encounter between a Centropages velificatus female and a Temora stylifera nauplius (Event 5 in Table 1) as seen in a stationary frame of reference. The left panel shows the video sequence from frame \#289080 to \#289101 (quasi-steady category); the right panel shows the video sequence from frame \#289101 to \#289134 (unsteady with body rotation category). The nauplius neither detected the upward swimming female nor her feeding current; the female detected the slowly moving nauplius when the tip of her A1 (first antenna) touched it; her resulting attack was unsuccessful. See Fig. 1 legend for explanation of velocity vector annotation appendages lead to different types of the self-generated flow. Even when the nauplius stops moving its appendages and remains motionless, there is still a flow going around the body due to free-sinking under the negative buoyancy of the body. Centropages velificatus nauplii move intermittently at $\sim 1$ short hop $\mathrm{s}^{-1}$; when they do not move, their 3 pairs of appendages are motionless. By contrast, Temora stylifera nauplii continuously move their 3 appendage pairs for producing a feeding current and a screw-like swimming motion. Paracalanus quasimodo nauplii move continuously in a gentle hop-like motion producing a spiral-like pattern, their A1 moving in a rhythm with the A2 (second antennae) and Md (mandibles). In view of different motion patterns of the appendages, the naupliar self-generated flow especially that around the nauplius' A1 is expected to affect the ability of the nauplius in detecting the hydrodynamic signals generated by a nearby predator. In this section, naupliar self-generated flows are examined for 3 typical motion patterns of naupliar appendages by using a modeling approach. (Table 2 lists all the symbols used in this paper.)

Fig. 7 shows the dorsal view of the morphological features of a Centropages velificatus nauplius (stage VI). The nauplius is $\sim 330 \mu \mathrm{m}$ in length and $140 \mu \mathrm{m}$ in width. The length of its A1 is $115 \mu \mathrm{m}$, and the longest A1 seta is $\sim 100 \mu \mathrm{m}$. The nauplius also has a pair of $\mathrm{A} 2$ and a pair of $\mathrm{Md}$, which are approximately the same length as the A1. Based on these morphological features, a model nauplius was designed and is also shown in Fig. 7. The model nauplius consists of a spherical main body and 6 point forces representing the net effects of the beating movement of the appendages (i.e. a pair of A1, A2 and Md if applicable). The spherical main body of the model nauplius is approximately the same volume as a real $C$. velificatus nauplius. If the real nauplius is assumed to be a prolate spheroid with a long axis of $330 \mu \mathrm{m}$ and a short axis of $140 \mu \mathrm{m}$, then the effective radius, $a_{n}$, of the model nauplius is calculated to be $93.16 \mu \mathrm{m}$. The application points for the point forces are $115 \mu \mathrm{m}$ (the length of an A1) away from the surface of the spherical main body. 
Centropages velificatus female vs. Paracalanus quasimodo nauplius

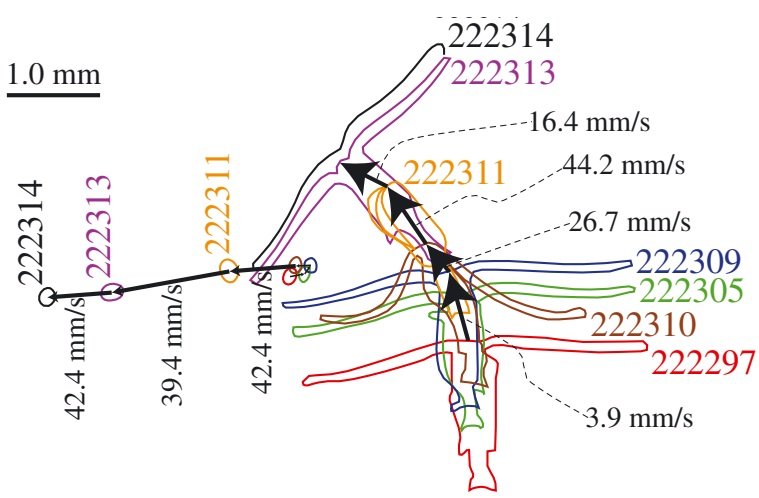

Fig. 6. Video sequence illustrating an encounter between a Centropages velificatus female and a Paracalanus quasimodo nauplius (Event 6 in Table 1, quasi-steady category before frame \#222309, at which time the female detected the nauplius at a distance of $\sim 0.2 \mathrm{~mm}$ from the tip of her A1) as seen in a stationary frame of reference. The female's ensuing attack was unsuccessful, and the nauplius responded vigorously to this strong attack. See Fig. 1 legend for explanation of velocity vector annotation

The characteristics of the naupliar self-generated flow around the A1 setae are examined by calculating the flow velocities of the naupliar generated flow along a line $\sim 100 \mu \mathrm{m}$ above the A1 tips (as shown in Fig. 7). We denote $\zeta$ as the local coordinate of this line and $\mathbf{u}(\zeta)$ as the distribution of the flow velocities along the line. (Also, the hydrodynamic signals potentially percepti-

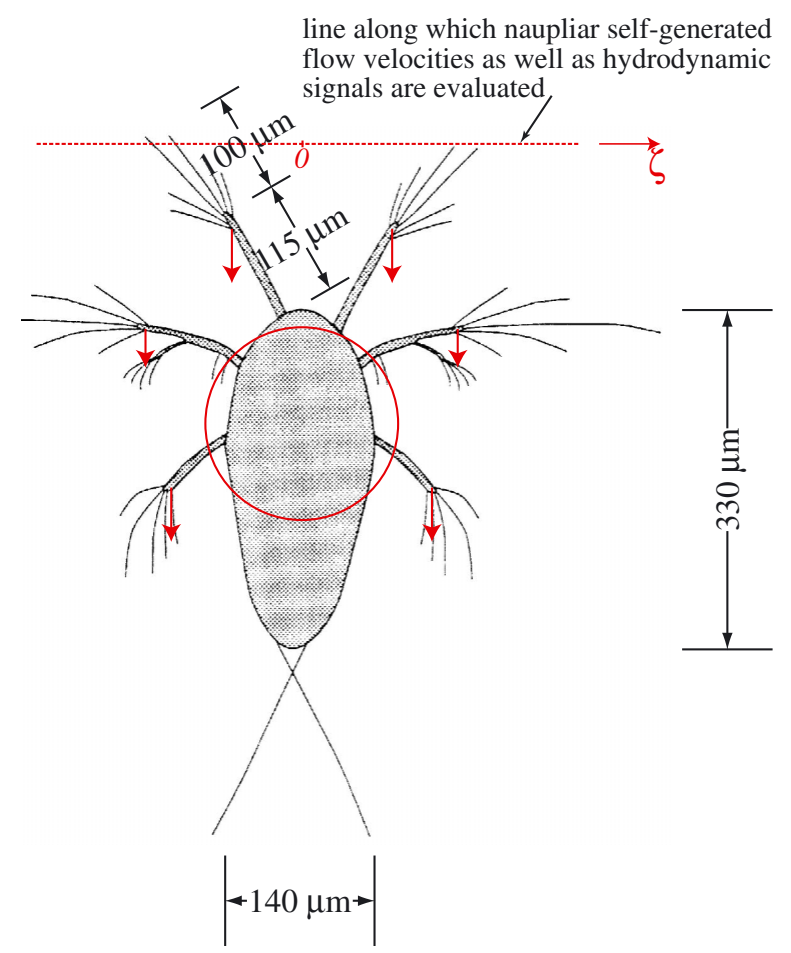

Fig. 7. Dorsal view of the morphological features of Centropages velificatus naupliar stage VI. A model nauplius is also shown in this figure, and consists of a spherical main body and 6 point forces representing the net effects of the beating movement of the appendages. Naupliar self-generated flow velocities as well as the hydrodynamic signals detected by the nauplius are quantified along the dashed line a short distance above the

A1 tips. The local coordinate of this line is denoted as $\zeta$

Table 2. Symbols used in this study

\begin{tabular}{|ll}
$\mathbf{x}$ & A vector from the center of the nauplius to an arbitrary point \\
$(x, y, z)$ & Frame of reference fixed on the nauplius, the origin of which is the center of the nauplius \\
$\left(x_{\mathrm{c}}, y_{\mathrm{c}}, z_{\mathrm{c}}\right)$ & Coordinates of the center of the female copepod in the frame of reference $(x, y, z)$ \\
$L$ & Body length of the female copepod \\
$D$ & Body width of the female copepod \\
$a_{\mathrm{c}}$ & Effective radius of the female copepod \\
$a_{\mathrm{n}}$ & Effective radius of the nauplius \\
$\Delta \rho_{\mathrm{n}}$ & Excess density of the nauplius \\
$W_{\text {excess }}$ & Excess weight of the female copepod \\
$g$ & Acceleration due to gravity \\
$\mu$ & Dynamic viscosity of water \\
$f^{k}$ & G=1, 2,3$),$ the 3 point forces representing the self-propelled swimming motion of the female copepod \\
$G$ & Green's function for an infinite flow bounded internally by a solid sphere \\
$\mathbf{U}$ & Swimming velocity of the female copepod, in a stationary frame of reference \\
$\mathbf{V}$ & Velocity of the nauplius, in a stationary frame of reference \\
$V_{\mathrm{s}}$ & Terminal sinking velocity of the female copepod \\
$V_{\mathrm{sn}}$ & Terminal sinking velocity of the nauplius \\
$u_{i}(\mathbf{x})$ & Components of the velocity field around the nauplius, in the absence of the female copepod, $i=1,2,3$, in the \\
$V_{i}(\mathbf{x})$ & frame of reference $(x, y, z)$ \\
$\zeta$ & Components of the velocity field around the nauplius, in the presence of the female copepod, $i=1,2,3$, in the \\
$\mathbf{u}(\zeta)$ & frame of reference $(x, y, z)$ \\
$\mathbf{v}(\zeta)$ & Local coordinate of the line a short distance above the nauplius' A1 tips \\
& Fluid velocity distribution along the line a short distance above the nauplius' A1 tips, in the absence of the \\
& female copepod \\
& Fluid velocity distribution along the line a short distance above the nauplius' A1 tips, in the presence of the
\end{tabular}


ble to the model nauplius are quantified along the same line in the next section.) The excess density, $\Delta \rho_{n}$, of the model nauplius is assumed to be $15 \mathrm{~kg} \mathrm{~m}^{-3}$, which lies in the range of the excess density of nauplii (e.g. Greenlaw \& Johnson 1982, Knutsen et al. 2001). The excess weight of the model nauplius is then calculated as:

$$
\frac{4}{3} \pi a_{n}^{3} \Delta \rho_{n} g
$$

where $g$ is the acceleration due to gravity, $\sim 9.8 \mathrm{~m} \mathrm{~s}^{-2}$.

Three typical motion patterns of naupliar appendages are considered. The first one is that the nauplius stops moving all its 3 pairs of appendages, so no point forces need to be applied in the hydrodynamic model for the nauplius. As a result, the nauplius sinks freely at its terminal sinking velocity, $V_{\mathrm{sn}}$, which is calculated as:

$$
\frac{2 a_{\mathrm{n}}^{2} \Delta \rho_{\mathrm{n}} g}{9 \mu}
$$

according to Stokes' law. Here, $\mu$ is the dynamic viscosity $\left(\sim 1.390 \times 10^{-3} \mathrm{~kg} \mathrm{~m}^{-1} \mathrm{~s}^{-1}\right.$ for sea water). The second pattern occurs when the nauplius beats its 3 pairs of appendages including the A1 and remains hovering in the water column. In order to describe this motion pattern, 3 pairs of point forces are applied ventrally to the spherical model nauplius. The third motion pattern considered involves the nauplius hovering in the water column by beating its one pair of A2 and one pair of Md while its A1 remain motionless. To model this motion pattern, only 2 pairs of point forces are applied. For the latter 2 motion patterns, the point forces applied are determined from the force-balance equation of the spherical model nauplius, i.e. the balance among excess weight, drag and reaction forces of the point forces applied. Then, the flow velocities around the spherical main body are determined. The whole process of calculating a flow field is similar to work done by Jiang et al. (2002a).

For the above-described 3 motion patterns of naupliar appendages, the naupliar self-generated flow velocities have been quantified along the line a short distance above the A1 tips (as sketched in Fig. 7). The velocities are calculated using a frame of reference fixed on the nauplius. The results are shown in Fig. 8. It can be seen that the free-sinking behavior (i.e. no appendage movement is involved) has the strongest self-generated flow field around the A1 among the 3 motion patterns considered. Furthermore, by comparing the 2 motion patterns with appendage movement involved, one can see that the behavior of freehovering with 6 moving appendages has slightly higher self-generated flow velocities around the A1 than the behavior of free-hovering with 4 moving appendages.

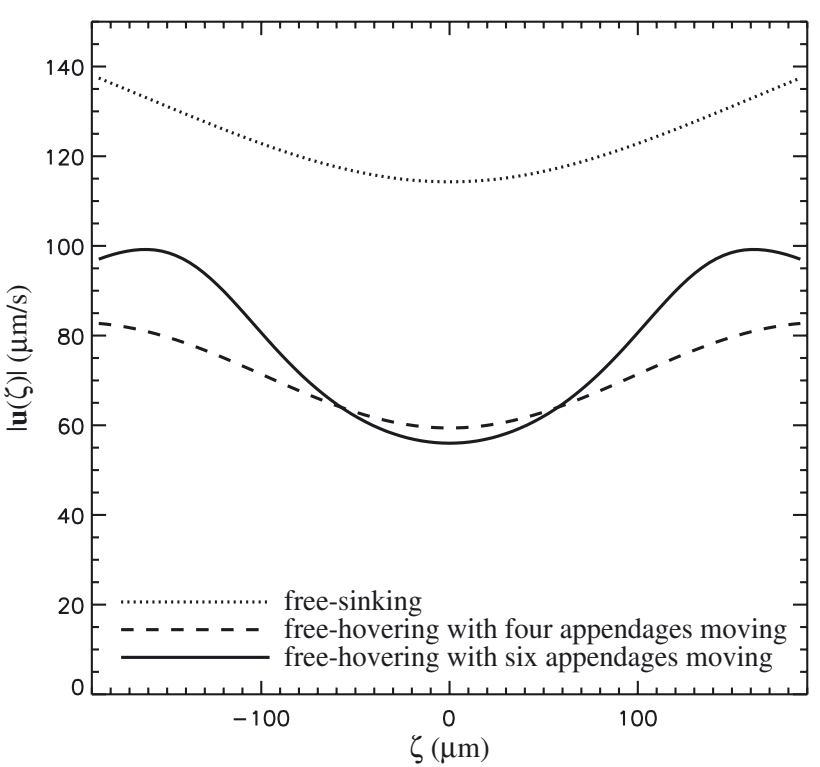

Fig. 8. Naupliar self-generated flow velocity distribution along the line a short distance above the A1 tips (as shown in Fig. 7) for 3 different motion patterns of naupliar appendages. The velocities are calculated using a frame of reference fixed on the nauplius

However, the flow velocity distributions as shown in Fig. 8 for the 2 motion patterns with appendage movement should be understood as the mean flow obtained by temporally averaging the time-dependent flow generated due to the beating movement of the appendages. Knowing the property of this timedependent flow is our primary interest. Nauplii of Centropages velificatus move intermittently with breaks ranging from a fraction of a second to several seconds. The movement usually consists of 5 to 7 strokes before they stop. The stroke frequency is between 30 and $37 \mathrm{~Hz}$. Concerning amplitudes of appendage movement of late stage nauplii of $C$. velificatus, their A1 moves backwards by 80 degrees which amounts to 100 to $120 \mu \mathrm{m}$ the distance covered at the tip of the A1, as the nauplius moves. The stroke frequency of nauplii of Temora stylifera ranges from 34.2 to $38.0 \mathrm{~Hz}$, mostly around $36 \mathrm{~Hz}$. The frequency of A1 motion of nauplii of Paracalanus aculeatus ranges from 18 to $20 \mathrm{~Hz}$.

We assume that the tip of A1 executes an oscillating movement described by $x(t)=-A \cos (2 \pi f t)$ so that the velocity of the tip of A1 is $u(t)=u_{0} \sin (2 \pi f t)$, where the amplitude of the oscillating velocity is $u_{0}=2 \pi f A$. Based on those observed features of the beating movement of naupliar appendages, the oscillating frequency, $f$, is assumed to be $25 \mathrm{~Hz}$, and the oscillating amplitude, $A$, is assumed to be $50 \mu \mathrm{m}$, so that $u_{0}$ is $7850 \mu \mathrm{m} \mathrm{s}^{-1}$. Finally, we estimate the flow velocity a distance, $d$, away from the tip of A1 using the solution to the 
problem of Stokes oscillating plate (Panton 1996, p 263-266):

$$
u \sim u_{0} \exp \left(-\frac{d}{\sqrt{v / \pi f}}\right) \sin \left(2 \pi f t-\frac{d}{\sqrt{v / \pi f}}\right)
$$

where $v$ is the kinematic viscosity $\left(=1.350 \times 10^{-6} \mathrm{~m}^{2}\right.$ $\mathrm{s}^{-1}$ ). To estimate the amplitude of the oscillating flow around the tip of an A1 seta of length of $100 \mu \mathrm{m}$, we substitute $d=100 \mu \mathrm{m}$ into Eq. 3, which gives the amplitude of $0.47 u_{0}$. Although above analysis is crude, it suggests that, when the A1 performs a beating movement, the flow around the A1 setae is of a highly oscillating nature. The amplitude of the oscillating flow is much larger than the time-averaged mean flow.

Modeling study of observed encounter events. A hydrodynamic model was developed for the quasisteady category. With this model, the hydrodynamic signals detected by the nauplius around the approaching female copepod are quantified for 2 encounter events depicted in Figs. 1 \& 2 respectively (Events 1 \& 2 , both of which are under the quasi-steady category). The hydrodynamic model includes a sub-model for the female copepod, which is used to model the flow field generated by the self-propelled motion of the female copepod (including its feeding current).

Sub-model for the female copepod: The female copepod is $\sim 1.2 \mathrm{~mm}$ in length $(L)$ and $0.4 \mathrm{~mm}$ in width $(D)$, so body volume is estimated as:

$$
\frac{\pi}{4} D^{2} L
$$

If the model copepod is assumed to have a spherical body shape with the same body volume as the real female copepod, the effective radius, $a_{C}$, of the copepod is then calculated as:

$$
\sqrt[3]{\frac{3}{16} D^{2} L}
$$

The female copepod's terminal sinking velocity, $V_{\mathrm{s}}$ is found to be $\sim 5.5 \mathrm{~mm} \mathrm{~s}^{-1}$ from 1 of our 15 encounter events (not shown). From Stokes' law, the excess weight of the copepod, $W_{\text {excess }}$ is estimated as $6 \pi \mu a_{\mathrm{c}} V_{\mathrm{s}}$ which is equivalent to an excess density of $\sim 32.2 \mathrm{~kg} \mathrm{~m}^{-3}$.

Under the quasi-steady category, the female copepod in a nauplius-copepod encounter event, by definition, remains in a quasi-steady motion. To model the flow field, a conclusion made by Jiang et al. (2002a) about the property of the flow field created by a copepod in steady swimming is used. Generally, the flow field created by the female copepod in a quasi-steady motion (e.g. swimming at a constant velocity $\mathbf{U}$ ) consists of 2 parts: one is the requirement to counterbalance the excess weight of the copepod, which is similar to the flow field due to a force monopole of intensity of the copepod's excess weight (Fig. 9a); the other is due to the copepod's self-propelled swimming motion, which is similar to the flow field due to a force dipole

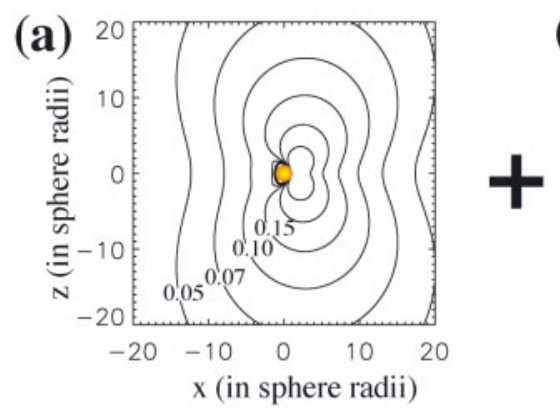

(d)

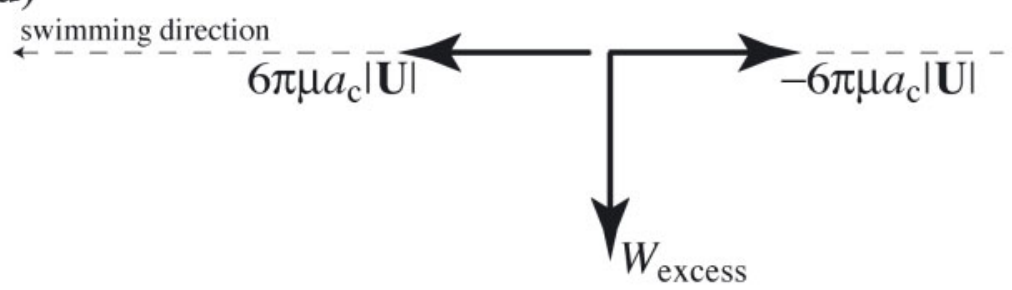

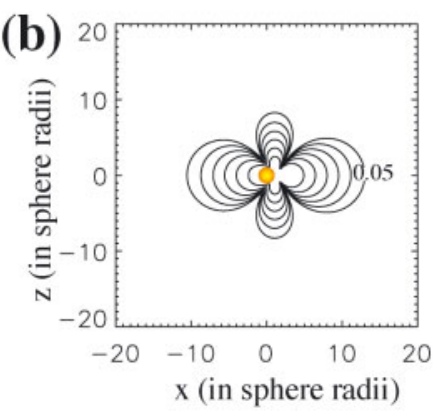
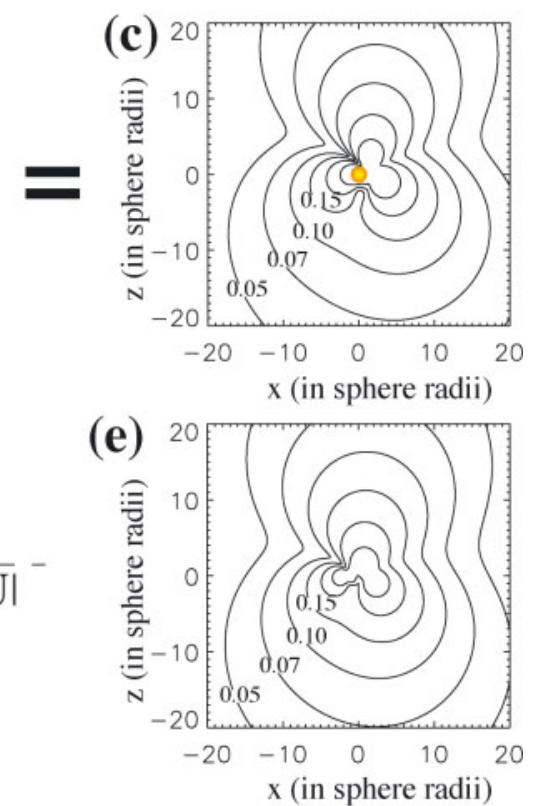

Fig. 9. Velocity contours (calculated relative to a stationary frame of reference) of the flow field (a) due to the requirement to counterbalance the copepod's excess weight (a force monopole), (b) due to the copepod's self-propelled swimming (a force dipole), and (c) due to the requirement to counterbalance the drag force by water and the copepod's excess weight, i.e. the addition of (a) and (b). The yellow circle at the center of panels (a), (b) and (c) illustrates the spherical model copepod. (d) Schematic illustration of the sub-model for a copepod swimming at a constant velocity $\mathbf{U}$, which includes a force monopole of intensity of the copepod's excess weight, $W_{\text {excess }}$ and a force dipole of intensity of $6 \pi \mu a_{\mathrm{c}}|\mathbf{U}|$. Here, $a_{\mathrm{c}}$ is the copepod's effective radius, and $\mu$ is the dynamic viscosity of water. (e) Velocity contours of the flow field calculated from the sub-model illustrated in (d) 
(Fig. 9b). The addition of these 2 parts forms the total flow field created by the copepod (Fig. 9c). Based on this, the flow field created by the female copepod is modeled as the addition of a force monopole of intensity of the copepod's excess weight and a force dipole of intensity of $6 \pi \mu a_{c}|\mathbf{U}|$ (the Stokes drag by the water on the copepod) (Fig. 9d). For simplicity (in order to obtain an analytical solution for the hydrodynamic model governing the flow disturbance generated by a copepod near a nauplius), the force dipole is approximated by 2 point forces - of the same intensity (i.e. $6 \pi \mu a_{\mathrm{c}}|\mathbf{U}|$ ) but opposite direction - one being applied along and the other against the swimming direction of the copepod, and the application points of the 2 point forces are separated by a certain distance in relation to $a_{c}$. These 2 application points are equally distant from the center of the spherical model copepod, and these 3 points are on the same line. Fig. 9e shows the velocity contours of the flow field calculated from this submodel for the female copepod. Although the submodel does not satisfy the no-slip boundary condition at the body surface of the female copepod, it fairly accurately reproduces the spatial decay of the flow field away from the body surface and even the flow field in the near field of the sphere (as we have assumed a spherical body shape to the female copepod). This can be seen by comparing Fig. 9e with Fig. 9c. The biggest discrepancy between our theoretical model and the real world may be that our model can not deal with a realistic body shape. However, the assumptions we have made for the sub-model are not worse than assuming a spherical body shape. To formulate a theoretical treatment, one has to simplify the body shape.

Hydrodynamic model in calculating the hydrodynamic signals: In Events 1 \& 2, the nauplius remained motionless and therefore sank freely at its terminal sinking velocity before it detected the approaching female copepod. Here, we denote $\mathbf{v}$ as the flow field around the nauplius generated solely due to free-sinking; this flow field is measured relative to a frame of reference fixed on the nauplius. When the female copepod is introduced into the vicinity of the nauplius, the flow field around the nauplius is generated due not only to the nauplius' freesinking but also to the self-propelled motion of the approaching female copepod. This flow field is denoted as $\mathbf{u}$, which is also measured relative to the frame of reference fixed on the nauplius. Thus, $\mathbf{u}-\mathbf{v}$ is the flow disturbance around the nauplius due to the presence of the female copepod. Using the previously described sub-model for the female copepod, $\mathbf{u}-\mathbf{v}$ is calculated as:

$$
u_{i}(\mathbf{x})-V_{i}(\mathbf{x})=\frac{1}{8 \pi \mu} \sum_{k} G_{i j}^{\mathrm{SPH}}\left(\mathbf{x}, \mathbf{x}_{0}^{k}\right) f_{j}^{k}
$$

where $G^{\mathrm{SPH}}$ is the Green's function for an infinite flow bounded internally by a solid sphere (see Jiang et al. 2002a for explanation), and $f^{k}(k=1,2,3)$ are the 3 point forces representing the self-propelled swimming movement of the female copepod (Fig. 10). The application point for the $k$ th point force is $\mathbf{x}_{0}^{k}$, which is in relation to the instantaneous position of the female copepod. Note that the swimming velocity of the female copepod is measured relative to the frame of reference fixed on the nauplius (Fig. 10). This swimming velocity is then used to determine 2 out of the 3 point forces via Stokes' law. The flow disturbance calculated from Eq. 6 satisfies the no-slip boundary condition imposed at the body surface of the nauplius, i.e. the flow disturbance is zero at the body surface of the nauplius.

Next, hydrodynamic signals potentially perceptible to the nauplius from the approaching female copepod are quantified along the line a short distance above the nauplius' A1 (Fig. 7). In fact, the flow disturbance is calculated along the line according to Eq. 6, which is then taken as the hydrodynamic signals. We denote the quantified hydrodynamic signals as $|\mathbf{u}(\zeta)-\mathbf{v}(\zeta)|$ with $\zeta$ as the local coordinate of the line a short distance above the nauplius' A1. For Events $1 \& 2$, it is assumed that the line denoted by $\zeta$ is aligned horizontally within the vertical plane of focus on which both the nauplius and the female copepod are located.

Modeling results: The hydrodynamic signals are quantified at 3 instant times between frame \#47050 and \#47070 for Event 1 (Fig. 11a) and between frame \#99780 and \#99797 for Event 2 (Fig. 11b). In view of the spatial extent of the A1 setae, the calculated flow disturbance from $\zeta=-2 a_{\mathrm{n}}$ to $2 a_{\mathrm{n}}$ is likely to be the hydrodynamic signals detected by the A1 setae, where $a_{\mathrm{n}}$ is the effective radius of the nauplius. Generally, as time increases (so that the distance between the nauplius and the copepod becomes shorter), the hydrodynamic signals become stronger. Also, the hydrodynamic sig-
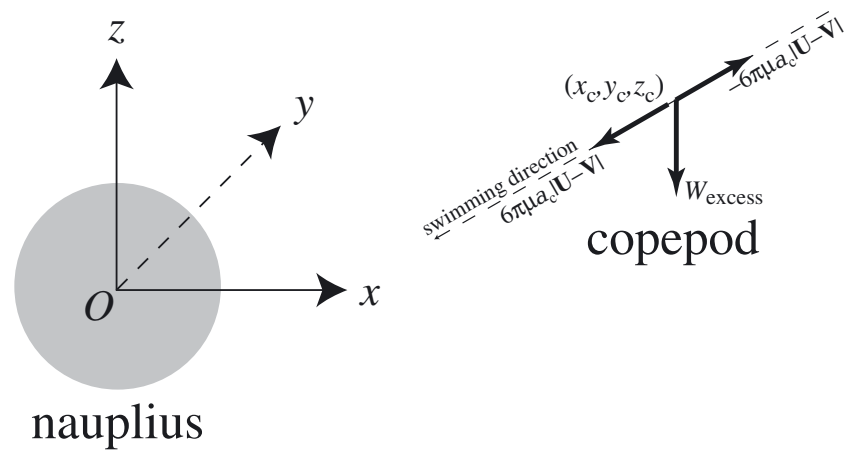

Fig. 10. Schematic illustration of the hydrodynamic model in calculating the flow field around a nauplius in the presence of a female copepod. Note that the copepod's swimming velocity, $\mathbf{U}-\mathbf{V}$, is measured in the frame of reference $(x, y, z)$ which is fixed on the nauplius, and the center of the nauplius is the origin of the frame of reference. The instantaneous position of the female copepod is $\left(x_{\mathrm{c}}, y_{\mathrm{c}}, z_{\mathrm{c}}\right)$ 

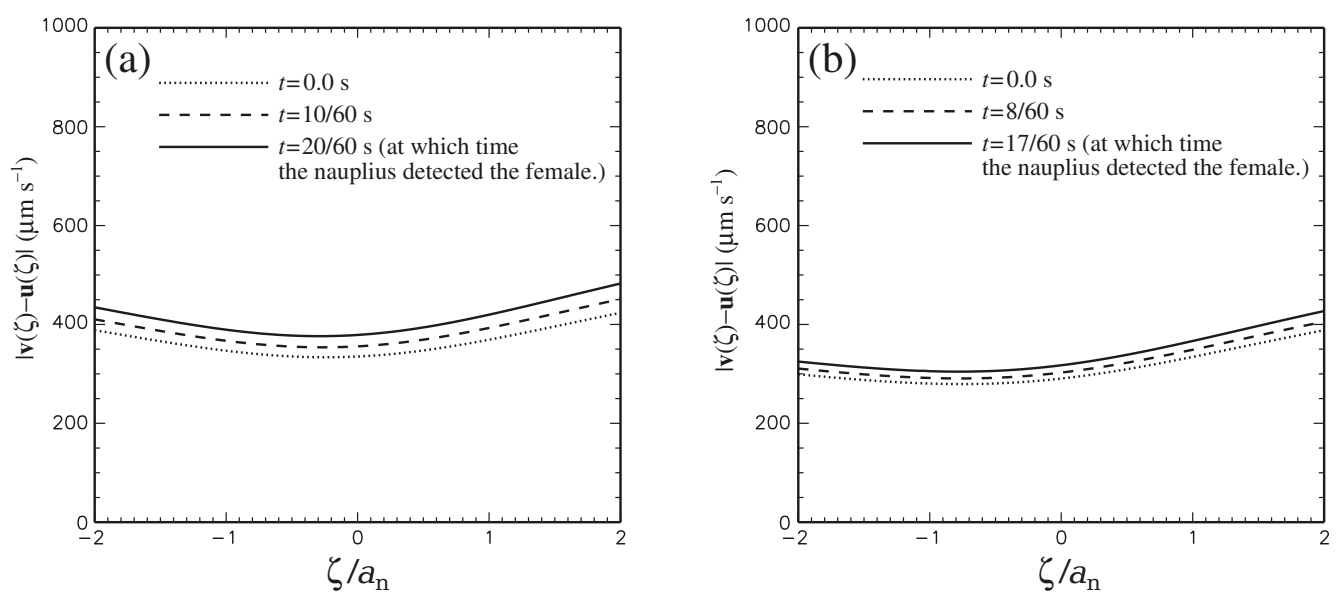

Fig. 11. Hydrodynamic signals quantified along the line a short distance above the A1 of the Centropages velificatus nauplius from the approaching $C$. velificatus female for (a) Event 1 in Table 1 (i.e. the encounter event shown in Fig. 1, quasi-steady category), for which the signals are quantified for 3 instant times from frame \#47050 to \#47070; (b) Event 2 in Table 1 (i.e. the encounter event shown in Fig. 2, quasi-steady category), for which the signals are quantified for 3 instant times from frame $\# 99780$ to $\# 99797$. Note that the horizontal axis is $\zeta / a_{n}$, i.e. the local coordinate, $\zeta$, of the line a short distance above the A1 of the nauplius, normalized by the effective radius, $a_{n}$, of the nauplius

nals quantified are stronger at the distal portions of the line denoted by $\zeta$. This may explain why the A1 setae are distributed radially around the A1 tips towards the space away from the main body. In this configuration, the hydrodynamic signals can be better detected.

For Event 1, at $t=20 / 60 \mathrm{~s}$ (at which time the nauplius detected the female copepod), the hydrodynamic signals between $\zeta=-2 a_{n}$ and $2 a_{n}$ are in the range of 376.3 to $482.8 \mu \mathrm{m} \mathrm{s}^{-1}$ (Fig. 11a). Since the no-slip boundary condition must be satisfied at the tip of A1 where A1 setae are located, the tip-base shear rates over the length of A1 setae may be calculated as:

$$
\text { tip-base shear rates } \equiv \frac{|\mathbf{u}(\zeta)-\mathbf{v}(\zeta)|}{\text { length of the longest A1 seta }}
$$

The tip-base shear rates are calculated in the range of 3.8 to $4.8 \mathrm{~s}^{-1}$ for the length of the longest A1 seta $(100 \mu \mathrm{m})$. Note that here the tip-base shear rates are not along the length of A1 itself but along the length (from tip to base) of an A1 seta. The resulting tip-base shear rates are indeed a distribution with respect to positions along the $\zeta$ line, reflecting that setae located at different positions feel different forces. For Event 2, at $t=17 / 60 \mathrm{~s}$ (at which time the nauplius detected the female copepod), the hydrodynamic signals between $\zeta=-2 a_{\mathrm{n}}$ and $2 a_{\mathrm{n}}$ are in the range of 304.6 to $427.1 \mu \mathrm{m}$ $\mathrm{s}^{-1}$ (Fig. 11b), and the tip-base shear rates are calculated in the range of 3.0 to $4.3 \mathrm{~s}^{-1}$ for the length of the longest A1 seta $(100 \mu \mathrm{m})$.

The hydrodynamic model is also applicable for the encounter events depicted in Fig. 5 (Event 5) from frame \#289080 to \#289099 and Fig. 6 (Event 6) from frame \#222297 to \#222309 since both the female copepod and the nauplius are approximately in steady motion during the specified frame numbers. A common feature of these 2 encounter events is that, at the final time (frame \#289099 in Fig. 5, or frame \#222309 in Fig. 6), the female copepod detected the nauplius, while the nauplius did not detect the female copepod. Here, the encounters were between a Centropages velificatus female and a Temora stylifera nauplius (Event 5), and between a C. velificatus female and a Paracalanus quasimodo nauplius (Event 6). The morphological parameters for these 2 naupliar species (cf. Paffenhöfer 1998) are as follows: T. stylifera N VI is $\sim 300 \mu \mathrm{m}$ in length and $125 \mu \mathrm{m}$ in width, the length of its $\mathrm{A} 1$ is $\sim 120 \mu \mathrm{m}$, and the longest A1 seta is $\sim 55 \mu \mathrm{m}$, P. quasimodo $\mathrm{N}$ VI is $\sim 270 \mu \mathrm{m}$ in length and $85 \mu \mathrm{m}$ in width, the length of its A1 is $~ 85 \mu \mathrm{m}$, and the longest A1 seta is $\sim 65 \mu \mathrm{m}$. These morphological parameters are used to calculate the effective radius $\left(a_{n}\right)$ of the nauplius and to determine the location of the line above the nauplius' A1 tips, where the hydrodynamic signals are quantified, as we have done before for C. velificatus nauplii. The hydrodynamic signals are quantified at 3 instant times between frame \#289080 and \#289099 for Event 5 (Fig. 12a), and between frame \#222297 and \#222309 for Event 6 (Fig. 12b). For Event 5, at $t=19 / 60 \mathrm{~s}$ (at which time the female copepod detected the nauplius, while the nauplius did not detect the female), the hydrodynamic signals between $\zeta=-2 a_{n}$ and $2 a_{n}$ are in the range of 464.1 to $628.5 \mu \mathrm{m}$ $\mathrm{s}^{-1}$, and the tip-base shear rates are calculated in the range of 8.4 to $11.4 \mathrm{~s}^{-1}$ for the length of the longest A1 seta $(55 \mu \mathrm{m})$. For Event 6 , at $t=12 / 60 \mathrm{~s}$ (at which time the female copepod detected the nauplius, while the nauplius did not detect the female), the hydrodynamic signals between $\zeta=-2 a_{n}$ and $2 a_{n}$ are in the range of 

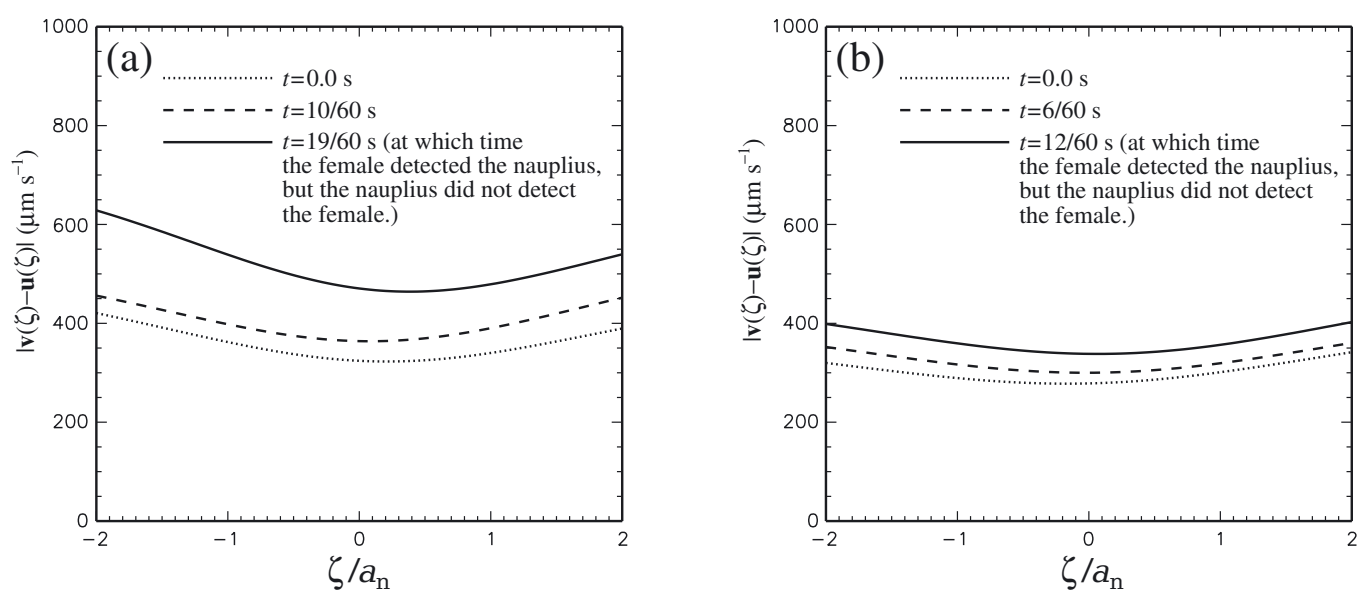

Fig. 12. (a) Hydrodynamic signals quantified along the line a short distance above the A1 of the Temora stylifera nauplius from the approaching Centropages velificatus female for the encounter event shown in Fig. 5 (Event 5 in Table 1), for which the signals are quantified for 3 instant times from frame \#289080 to \#289099 (quasi-steady category in these frames). (b) Hydrodynamic signals quantified along the line a short distance above the A1 of the Paracalanus quasimodo nauplius from the approaching $C$. velificatus female for the encounter event shown in Fig. 6 (Event 6 in Table 1), for which the signals are quantified for 3 instant times from frame \#222297 to \#222309 (quasi-steady category in these frames). Note that the horizontal axis is $\zeta / a_{n}$, i.e. the local coordinate, $\zeta$, of the line a short distance above the A1 of the nauplius, normalized by the effective radius, $a_{\mathrm{n}}$, of the nauplius

338.1 to $402.6 \mu \mathrm{m} \mathrm{s}^{-1}$, and the tip-base shear rates are calculated in the range of 5.2 to $6.2 \mathrm{~s}^{-1}$ for the length of the longest A1 seta $(65 \mu \mathrm{m})$. For Events $5 \& 6$, the calculated hydrodynamic signals and tip-base shear rates, both presumably detectable to the nauplius, are comparable with or even stronger than those previously calculated for the 2 encounter events between a $C$. velificatus female and a $C$. velificatus nauplius (Events 1 \& 2). However, the difference in the outcome is obvious.

Noise from the tip-base shear rates of the naupliar self-generated flow: We have shown that the mechanoreceptive sensitivities are different for 3 copepod naupliar species in detecting the flow disturbance generated due to a steadily approaching Centropages velificatus female. When the tip-base shear rates along its A1 setae were in the range of 3.8 to $4.8 \mathrm{~s}^{-1}$ in Event 1 and 3.0 to $4.3 \mathrm{~s}^{-1}$ in Event 2, both C. velificatus nauplii detected the approaching $C$. velificatus female. In contrast, when the tip-base shear rates along its A1 setae were in the range of 8.4 to $11.4 \mathrm{~s}^{-1}$ for the Temora stylifera nauplius and 5.2 to $6.2 \mathrm{~s}^{-1}$ for the Paracalanus quasimodo nauplius, neither of them detected the approaching $C$. velificatus female. The different outcomes may be explained by examining the noise field of tip-base shear rates resulting from the naupliar selfgenerated flow for each of the 3 naupliar species. For the $C$. velificatus nauplius not beating its appendages, the tip-base shear rates of the naupliar self-generated flow along the length of A1 setae are in the range of 1.1 to $1.2 \mathrm{~s}^{-1}$ according to the results reported in Fig. 8 between $\zeta=-2 a_{n}$ and $2 a_{n}$. Thus, the noise level is only $\sim 25 \%$ of the level of the hydrodynamic signals at the time when the detection occurs. For the T. stylifera/ $P$. quasimodo nauplii which were continuously beating their 3 pairs of appendages, the tip-base shear rates of the naupliar generated flow along the length of A1 setae are of a highly oscillating nature. The magnitude of the oscillating is much higher than the range of the tip-base shear rates resulting from an approaching C. velificatus female, in our estimation. Thus, the noise level is much higher than the signal level for T. stylifera/P. quasimodo nauplii.

\section{DISCUSSION}

In this study, we have developed a hydrodynamic model for the quasi-steady category. The flow field due to the self-propelled motion of the female copepod is modeled as the addition of a force monopole (reflecting the effect of the female copepod's excess weight) and a force dipole (reflecting the effect of the female copepod's self-propelled quasi-steady swimming). The model has been utilized to quantify the hydrodynamic signals potentially perceptible to the nauplius for 4 observed encounter events (i.e. Events 1, 2, 5 \& 6 in Table 1). To quantify the hydrodynamic signals for the other 2 categories, different hydrodynamic models have to be developed in order to reflect the differences in the motion behavior of the female copepod. For the unsteady category, the unsteady force associated with the linear accelerated/decelerated movement of the female copepod has to be considered. For the unsteady with body rotation category, the unsteady torque associated with the body rotation of the female copepod 
Table 3. Threshold deformation rates required for copepod nauplii of various species to elicit escapes when responding to hydrodynamic disturbances

\begin{tabular}{|c|c|c|c|c|c|}
\hline \multicolumn{2}{|c|}{ Species and stage } & $\begin{array}{l}\text { Threshold deformation } \\
\text { rate }\left(\mathrm{s}^{-1}\right)\end{array}$ & \multirow{3}{*}{$\begin{array}{l}\begin{array}{c}\text { Hydrodynamic } \\
\text { disturbance }\end{array} \\
\text { Flow generated by } \\
\text { a suction pipette } \\
\text { (i.e. siphon flow) }\end{array}$} & \multirow{2}{*}{$\begin{array}{c}\text { Source } \\
\begin{array}{c}\text { Kiørboe et al. } \\
\text { (1999) }\end{array}\end{array}$} & \multirow{3}{*}{$\begin{array}{l}\begin{array}{l}\text { Approach to obtain the } \\
\text { threshold deformation rate }\end{array} \\
\text { Deformation rate was calcu- } \\
\text { lated at the start point of jump } \\
\text { using a formula for the siphon }\end{array}$} \\
\hline $\begin{array}{l}\text { Acartia } \\
\text { tonsa }\end{array}$ & $\begin{array}{l}\text { N I-N II } \\
\text { N IV-N V }\end{array}$ & $\begin{array}{l}2.49 \\
1.19\end{array}$ & & & \\
\hline $\begin{array}{l}\text { Calanus } \\
\text { helgolandicus }\end{array}$ & $\begin{array}{l}\text { N I-N II } \\
\text { N IV-N V }\end{array}$ & $\begin{array}{l}0.52 \\
3.24\end{array}$ & & $\begin{array}{c}\text { Titelman \& } \\
\text { Kiørboe (2003) }\end{array}$ & \\
\hline $\begin{array}{l}\text { Centropages } \\
\text { typicus }\end{array}$ & $\begin{array}{l}\text { N I-N II } \\
\text { N IV-N V }\end{array}$ & $\begin{array}{l}2.60 \\
2.79\end{array}$ & & " & $\begin{array}{l}\text { take into account the effects } \\
\text { due to the finite-sized body } \\
\text { morphology and the no-slip }\end{array}$ \\
\hline $\begin{array}{l}\text { Eurytemora } \\
\text { affinis }\end{array}$ & $\begin{array}{l}\text { N I-N II } \\
\text { N IV-N V }\end{array}$ & $\begin{array}{l}1.88 \\
2.65\end{array}$ & & $"$ & $\begin{array}{l}\text { boundary condition imposed at } \\
\text { the surface of the nauplius that }\end{array}$ \\
\hline $\begin{array}{l}\text { Euterpina } \\
\text { acutifrons }\end{array}$ & $\begin{array}{l}\text { N I-N II } \\
\text { N IV-N V }\end{array}$ & $\begin{array}{l}4.25 \\
1.92\end{array}$ & & $"$ & $\begin{array}{l}\text { was immersed in the siphon } \\
\text { flow. }\end{array}$ \\
\hline $\begin{array}{l}\text { Temora } \\
\text { longicornis }\end{array}$ & $\begin{array}{l}\text { N II-N III } \\
\text { N V-N VI }\end{array}$ & $\begin{array}{l}2.78 \\
3.96\end{array}$ & & Titelman (2001) & \\
\hline
\end{tabular}

has to be considered, along with the unsteady force, if applicable.

Several studies have documented threshold deformation rates required to elicit escape responses from nauplii of various copepod species in response to hydrodynamic disturbances (Table 3). Generally, the approach is to expose the nauplii to a certain type of flow field generated either biologically or artificially and to record where the first escape response of the nauplii occurs. When a flow field is generated artificially, there should be a formula describing the flow velocity field (e.g. Kiørboe et al. 1999). Then, the threshold deformation rates are calculated from the formulated flow velocity field at the positions recorded. Similar approaches have been utilized to obtain the threshold deformation rates for adult copepods (Haury et al. 1980, Viitasalo et al. 1998, Kiørboe et al. 1999). However, these threshold deformation rates are not those experienced by the sensory organs, such as the A1 setae, of the nauplii. This is because the finite-sized body morphology (e.g. the body shape and size, lengths and spatial distribution of the appendages, lengths and spatial distribution of the setae on the appendages) and the no-slip boundary condition imposed at the surface of the nauplius may to some extent modify the final hydrodynamic signals detected by the sensory organs. To demonstrate this point, we have calculated the deformation rates along the trajectory of a nauplius immersed in the flow field generated by a female copepod for the encounter event shown in Fig. 1 (Event 1, quasi-steady category) for the time interval from frame \#47050 to \#47070, without considering the existence of the nauplius
(Fig. 13). The calculated 'undisturbed' deformation rates are much different from the previously calculated tip-base shear rates along the length of A1 setae. The 'undisturbed' deformation rate is only $\sim 0.27 \mathrm{~s}^{-1}$ at the position where the nauplius detected the female copepod. Many problems, such as the effects of the body size, the effects of the morphology of the sensory organs (i.e. the lengths and 3-dimensional distribution of A1 setae), the noise field due to naupliar selfgenerated flow, etc., can only be elucidated by examining the hydrodynamic signals at the scale size of the sensory organs. Flow visualization/measurement techniques, which can provide flow information at the scale size of the sensory organs or least at the scale size of the individual nauplius being exposed to hydrodynamic disturbances, are desired. Hydrodynamic models designed to study the mechanoreception between a prey and a predator may also have to consider the effects of both the finite-sized body morphology of the signal receiver and the no-slip boundary

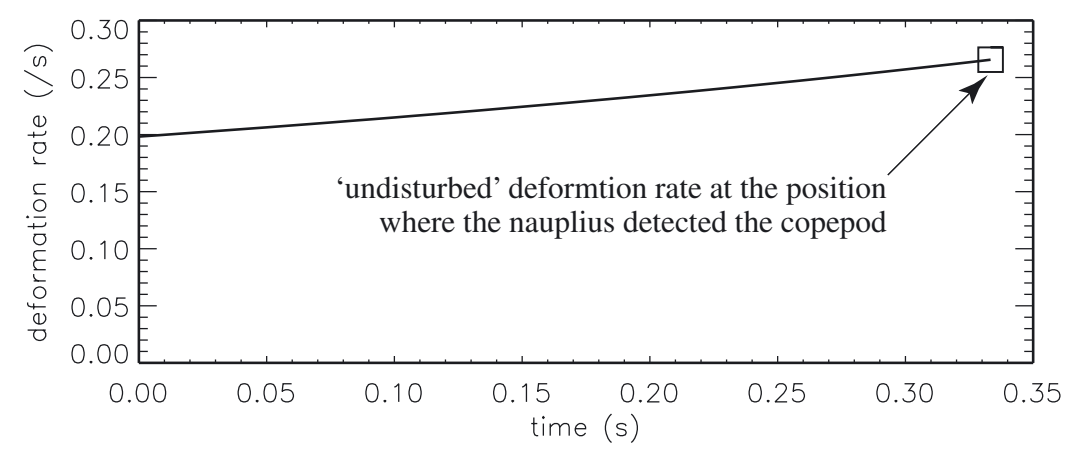

Fig. 13. 'Undisturbed' deformation rates calculated along the trajectory of the nauplius immersed in the flow field generated by the female copepod for Event 1 in Table 1 (i.e. the encounter event shown in Fig. 1, quasi-steady category) for the time interval from frame \#47050 to \#47070. Here, 'undisturbed' means that the flow field generated by the female copepod is calculated without considering the existence of the nauplius 
condition imposed at the surface of the signal receiver by the hydrodynamic disturbances generated.

Although the threshold deformation rates determined for copepod nauplii in the previous studies were not those experienced by the sensory organs of copepod nauplii, they have revealed that sensitivity to hydrodynamic signals varies with the motion behavior of the nauplii. Our results also suggest this same trend. Titelman \& Kiørboe (2003) have further discussed this trend in terms of detectability and volume encounter with copepod predators by means of simple hydrodynamic models. In the present work, we have demonstrated the causal effect of the naupliar self-generated flow on this trend. Intuitively, the naupliar selfgenerated flow is determined by the motion behavior of the nauplii so different motion behaviors lead to different flows. The naupliar self-generated flow can be described as the noise field, as opposed to that of the signal field of the hydrodynamic disturbances generated by nearby predators. Our modeling study has shown that, during a motionless, free-sinking period, the noise field around an occasionally moving nauplius (jump-sink) is much weaker than that around a nauplius moving its cephalic appendages continuously to achieve a smooth and continuous motion pattern. As a result, the former has a higher sensitivity to the hydrodynamic signals than the latter.

This higher sensitivity is in accordance with earlier empirical studies in which significantly more nauplii of Temora turbinata were ingested than were Centropages velificatus/furcatus nauplii by females of $C$. velificatus/furcatus and Temora stylifera (Paffenhöfer \& Knowles 1980). The above-mentioned differences in sensitivity were also apparent when comparing reaction distances of nauplii of $C$. velificatus and T. stylifera to the feeding current created by tethered females of T. stylifera. C. velificatus nauplii reacted to the feeding current at an average distance of $1.85 \mathrm{~mm}( \pm 0.16 \mathrm{SE}$, $\mathrm{n}=31$ ) from the tip of the female's cephalon, and T. stylifera nauplii at $1.33 \mathrm{~mm}( \pm 0.12 \mathrm{SE}, \mathrm{n}=31, \mathrm{G}$. A. Paffenhöfer, unpubl. obs.). From these findings we would have expected that continuously moving nauplii would be captured at a higher rate than those moving intermittently. Our preliminary empirical observations do not confirm these findings. With individually observed free-swimming $C$. velificatus females as predators, $4.6 \%(\mathrm{n}=43)$ of all encounters with nauplii of $C$. velificatus resulted in a capture, $4.9 \%$ with $T$. stylifera nauplii $(\mathrm{n}=61)$, and $5.8 \%$ with Paracalanus quasimodo nauplii $(\mathrm{n}=52)$. About every fifth capture attempt made by female $C$. velificatus resulted in a successful capture $(18.1 \%, C$. velificatus nauplii, $\mathrm{n}=11 ; 18.8 \%$ T. stylifera nauplii, $\mathrm{n}=16$; and $21.2 \%, P$. quasimodo nauplii, $\mathrm{n}=14$ ). There are discrepancies between these recent observations and our model (as well as results presented by Paffenhöfer \& Knowles 1980), which may be due to insufficient number of taped observations, which resulted in a total of only 8 captures. It would be necessary to increase our empirical observations by factor of at least 5 for a meaningful statistical analysis. Simultaneously, we need to apply our hydrodynamic model to more available empirical observations.

Our long-term goal is to apply our model to the environment i.e. the southeastern continental shelf of the US. There, nauplius concentrations during summer range from near 10 to more than 50 nauplii $\mathrm{l}^{-1}$ on the middle to outer shelf (Paffenhöfer et al. 1984). These nauplius concentrations are not reflected in the abundance of copepodid stages and adults. The probability of pronounced predation by omnivorous copepods on nauplii, including predation by copepodid stages, is high, despite the occasional abundance of pelagic coelenterates. To achieve our goal, nauplii of other abundant copepod species as well as other abundant omnivores will have to be included in our analyses.

Acknowledgements. This research was supported by a grant from the National Science Foundation (NSF OCE 90-00144). Many of the videotapes were made and analyzed by K. D. Lewis. This support is gratefully acknowledged. HJ gratefully acknowledges the National Science Foundation (NSF OCE0323959), the Postdoctoral Scholar Program at the Woods Hole Oceanographic Institution (WHOI) with funding provided by the Dr. George D. Grice Postdoctoral Scholarship Fund, and the Penzance Endowed Fund in Support of Assistant Scientists at WHOI. This is WHOI contribution number 11066 .

\section{LITERATURE CITED}

Anraku M, Omori M (1963) Preliminary survey of the relationship between the feeding habit and the structure of the mouthparts of marine copepods. Limnol Oceanogr 8: $116-126$

Bowman TE (1971) The distribution of calanoid copepods off the southeastern United States between Cape Hatteras and southern Florida. Smithsonian Contrib Zool No. 96

Bundy MH, Gross TF, Vanderploeg HA, Strickler JR (1998) Perception of inert particles by calanoid copepods: behavioral observations and a numerical model. J Plankton Res 20:2129-2152

Buskey EJ, Coulter C, Strom S (1993) Locomotory patterns of microzooplankton: potential effects of food selectivity of larval fish. Bull Mar Sci 53:29-43

Donaghay PL, Small LT (1979) Food selection capabilities of the estuarine copepod Acartia clausii. Mar Biol 52: $137-146$

Eiane K, Aksnes DL, Ohman MD, Wood S, Martinussen MB (2002) Stage-specific mortality of Calanus spp. under different predation regimes. Limnol Oceanogr 47:636-645

Fryer G (1986) Structure, function and behaviour, and the elucidation of evolution in copepods and other crustaceans. Syllogeus 58:150-157

Gauld DT (1966) The swimming and feeding of planktonic copepods. In: Barnes H (ed) Some contemporary studies 
in marine science. Allen and Unwin, London, p 313-334 Gerritsen J, Strickler JR (1977) Encounter probabilities and community structure in zooplankton: a mathematical model. J Fish Res Bd Can 34:73-82

Greenlaw CF, Johnson RK (1982) Physical and acoustical properties of zooplankton. J Acoust Soc Am 72:1706-1710

Hart RC (1997) Naupliar and copepodite growth and survival of two freshwater calanoids at various food levels: demographic contrasts, similarities, and food needs. Limnol Oceanogr 41:648-658

Haury LR, Kenyon DE, Brooks JR (1980) Experimental evaluation of the avoidance reaction of Calanus finmarchicus. J Plankton Res 2:187-202

Jiang H, Osborn TR, Meneveau C (2002a) The flow field around a freely swimming copepod in steady motion: Part I theoretical analysis. J Plankton Res 24:167-189

Jiang H, Osborn TR, Meneveau C (2002b) Hydrodynamic interaction between two copepods: a numerical study. J Plankton Res 24:235-253

Kerfoot WC (1978) Combat between predatory copepods and their prey: Cyclops, Epischura and Bosmina. Limnol Oceanogr 23:1089-1102

Kiørboe T, Sabatini M (1994) Reproductive and life-cycle strategies in egg-carrying cyclopoid and free-spawning calanoid copepods. J Plankton Res 16:1353-1366

Kiørboe T, Visser AW (1999) Predator and prey perception in copepods due to hydromechanical signals. Mar Ecol Prog Ser 179:81-95

Kiørboe T, Saiz E, Visser AW (1999) Hydrodynamic signal perception in the copepod Acartia tonsa. Mar Ecol Prog Ser 179:97-111

Knutsen T, Melle W, Calise L (2001) Determining the mass density of marine copepods and their eggs with a critical focus on some of the previously used methods. J Plankton Res 23:859-873

Landry MR (1978) Predatory feeding behavior of the marine copepod, Labidocera trispinosa. Limnol Oceanogr 23: 1103-1113

Landry MR, Fagerness VL (1988) Behavioral and morphological influences on predatory interactions among marine copepods. Bull Mar Sci 43:509-529

Marine Zooplankton Colloquium 1 (1989) Future marine zooplankton research - a perspective. Mar Ecol Prog Ser 55: 197-206

Mullin MM, Brooks ER (1970) Production of the planktonic copepod, Calanus helgolandicus. In: Strickland JDH (ed) The ecology of the plankton off La Jolla, California, in the period April through September, 1967. Bull Scripps Inst Oceanogr Un Calif 17:89-103

Ohman MD (1988) Behavioral responses of zooplankton to predation. Bull Mar Sci 43:530-550

Editorial responsibility: Otto Kinne (Editor),

Oldendorf/Luhe, Germany
Ohman MD, Wood SN (1995) The inevitability of mortality. ICES J Mar Sci 52:517-522

Paffenhöfer GA (1970) Cultivation of Calanus helgolandicus under controlled conditions. Helgol Wiss Meeresunters 20:346-359

Paffenhöfer GA (1998) On the relation of structure, perception and activity in marine planktonic copepods. J Mar Syst 15:457-473

Paffenhöfer GA, Knowles SC (1980) Omnivorousness in marine planktonic copepods. J Plankton Res 2:355-365

Paffenhöfer GA, Mazzocchi MG (2002) On some aspects of the behavior of Oithona plumifera (Copepoda: Cyclopoida). J Plankton Res 24:129-135

Paffenhöfer GA, Wester BT, Nicholas, WD (1984) Zooplankton abundance in relation to state and type of intrusions onto the southeastern United States shelf during summer. J Mar Res 42:995-1017

Paffenhöfer GA, Strickler JR, Lewis KD, Richman S (1996) Motion behavior of nauplii and early copepodid stages of marine planktonic copepods. J Plankton Res 18: 1699-1715

Panton RL (1996) Incompressible flow. John Wiley \& Sons, New York

Strickler JR (1985) Feeding currents in calanoid copepods: two new hypotheses. Symp Soc Exp Biol 89:459-485

Strickler JR, Bal AK (1973) Setae of the first antennae of the copepod Cyclops scutifer (Sars): their structure and importance. Proc Natl Acad Sci USA 70:2656-2659

Svensen C, Kiørboe T (2000) Remote prey detection in Oithona similis: hydromechanical versus chemical cues. J Plankton Res 22:1155-1166

Tiselius P, Jonsson PR (1990) Foraging behavior of six calanoid copepods: observations and hydrodynamic analysis. Mar Ecol Prog Ser 66:23-33

Titelman J (2001) Swimming and escape behavior of copepod nauplii: implications for predator-prey interactions among copepods. Mar Ecol Prog Ser 213:203-213

Titelman J, Kiørboe T (2003) Predator avoidance by nauplii. Mar Ecol Prog Ser 247:137-149

Viitasalo M, Kiørboe T, Flinkman J, Pedersen LW, Visser AW (1998) Predation vulnerability of planktonic copepods: consequences of predator foraging strategies and prey sensory abilities. Mar Ecol Prog Ser 175:129-142

Visser AW (2001) Hydromechanical signals in the plankton. Mar Ecol Prog Ser 222:1-24

Yen J (1988) Directionality and swimming speeds in predatorprey and male-female interactions of Euchaeta rimana, a subtropical marine copepod. Bull Mar Sci 43:395-403

Yen J, Lenz PH, Gassie DV, Hartline DK (1992) Mechanoreception in marine copepods: electrophysiological studies on the first antennae. J Plankton Res 14:495-512

Submitted: September 23, 2003; Accepted: April 6, 2004

Proofs received from author(s): August 18, 2004 